\title{
Synthesis, surface characterization and electrokinetic properties of colloidal silica nanoparticles with magnetic core
}

\author{
Karolina Gdula ${ }^{1}$ Andrzej Dąbrowski ${ }^{1}$ Ewa Skwarek $^{2}$
}

Received: 30 October 2015/Revised: 21 December 2015/Accepted: 30 December 2015/Published online: 7 January 2016

(C) The Author(s) 2016. This article is published with open access at Springerlink.com

\begin{abstract}
In order to obtain functionalized silica colloids with magnetic properties, the three-step reaction, was carried out. The aqueous suspension of iron oxide nanoparticles as magnetic core (maghemite- $\gamma-\mathrm{Fe}_{2} \mathrm{O}_{3}$ ) was synthesized according to the Massart's method (Massart in IEEE Trans Magn 17:1247-1248, 1981). A silica shell was obtained onto maghemite employing a modified sol-gel method by Salgueirino (Salgueirino-Maceira et al. in Adv Mater 19:4131-4144, 2006). As-synthesized magnetic silica core/shell nanocomposites were further functionalized by the post-grafting approach, using (3-Aminopropyl)trimethoxysilane (APTMS) (Pham et al. in Langmuir 18:4915-4920, 2002). The obtained materials were characterized by nitrogen adsorption/desorption measurements, $\mathrm{X}$-ray powder diffractometry (XRD), transmission electron microscopy (TEM). Particle sizes were measured by diffraction laser (DL). In order to establish colloidal stability of the system, zeta potential were measured. The syntheses routes led to obtain both, good purity of maghemite particles (more than $90 \%$ ) and their good coverage by outer silica shell. Thanks to their nanometer size and surface properties (especially, presence of amino groups which can ensure the electrostatic interaction between surface of adsorbent and adsorbate molecules), asprepared nanocomposites can be considered as promising
\end{abstract}

Karolina Gdula

karolina.gdula@poczta.umcs.lublin.pl

1 Department of Theoretical Chemistry, Maria CurieSklodowska University, Maria Curie-Sklodowska Sq. 3, 20031 Lublin, Poland

2 Department of Radiochemistry and Colloid Chemistry, Maria Curie-Sklodowska University, Maria Curie-Sklodowska Sq. 3, 20031 Lublin, Poland adsorbents. It can be found in the literature, that such systems are used in medicine as targeted drug delivery systems (Chen et al. in $\mathrm{J}$ Magn Magn Mater 322:2439-2445, 2010; Bele et al. in J Chromatogr B $867: 160-164,2008)$ or in environment protection as magnetically removable adsorbents (Giakisikli and Anthemidis in Anal Chim Acta 789:1-16, 2013; Tural et al. in J Phys Chem Solids 72:968-973, 2011).

Keywords Magnetic nanoparticles · Core/shell structures $\cdot$ Zeta potential $\cdot$ Size

\section{Introduction}

In the last two decades, an increased development in the field of meso- and nanoscience has been achieved. Especially, in the field of colloidal science, in which materials have at least one characteristic dimension in the range of $1 \mathrm{~nm}$ to $1 \mu \mathrm{m}$ (Xia et al. 2000). Inorganic colloidal particles are small objects which are dispersed in solvent. Nowadays, so-called core/shell structures are of great interest among researchers in many scientific groups. Such objects can deliver many interesting properties, which cannot be ensured by singular particles. Core/shell hybrid materials can be composed of different core materials, which are characterized by many interesting properties, such as: magnetic (Hyeon 2002; Deng et al. 2008; Kim et al. 2008), fluorescence (Tovmachenko et al. 2006; Reiss et al. 2009), luminescent (Mahmoudi et al. 2011) etc. Especially, superparamagnetic iron oxide nanoparticles (SPIONs) (Salgueirino-Maceira and Correa-Duarte 2007) are promising materials for many biomedical applications, such as hyperthermia treatment (Laurent et al. 2011), magnetic resonance imaging (MRI) (Schlorf et al. 2011), 
targeted drug delivery systems, especially in cancer treatment (Laurent and Mahmoudi 2011; Rosena et al. 2012; Wahajuddin and Arora 2012), magnetically removable catalysts (Lee and Lee 2008) and, more recently, as magnetically removable adsorbents (Tang and Lo 2013; Zhang et al. 2008). Nevertheless, there is a need to modify their surface in order to improve their biocompatibility and biodegradability. Thus, the above-mentioned magnetic cores can be modified with a broad range of outer shells, e.g. silica (Yi et al. 2005; Guerrero-Martinez et al. 2010) or polymers (Gupta and Gupta 2005; Rudzka et al. 2012; Guo et al. 2005). The surface modification of magnetic nanoparticles is crucial for the control of their chemical and physical properties, and colloidal stability, which is very important in their further applications. As mentioned above, SPIONs are very attractive in many biological applications due to the fact that they are highly biocompatible and biodegradable, as well as suitable for surface modification in order to improve those properties. What is more, the surface functionalization by outer shells provides them with a steric barrier against agglomeration.

A form of matter arrangement called the double electrical layer is created at the solid/electrolyte interface. There are some literature reports about $\alpha-\mathrm{Fe}_{2} \mathrm{O}_{3}$. The novelty of the paper is characterization of the core/sell structures/electrolyte interface (Chibowski and Janusz 2002).

In this work, we present synthesis, surface characterization and zeta potential measurement of the synthesized nanoparticles composed of magnetic core and silica shell, as well as those core/shell structures functionalized with amine groups. Effects of $\mathrm{pH}$ and ionic strength on the zeta potential properties of the above-mentioned nanocomposites, were examined.

\section{Experimental}

\subsection{Reagents}

The following compounds were used: $\mathrm{FeCl}_{3} \cdot 6 \mathrm{H}_{2} \mathrm{O}$ (Chempur), $\mathrm{FeCl}_{2} \cdot 4 \mathrm{H}_{2} \mathrm{O}$ (Chempur), $\mathrm{NH}_{4} \mathrm{OH}(30 \%$, Chempur), $\mathrm{HCl}\left(37 \%\right.$, Chempur), $\mathrm{FeNO}_{3} \cdot 9 \mathrm{H}_{2} \mathrm{O}$ (POCH), $\mathrm{HNO}_{3}(65 \%, \mathrm{POCH})$, tetraethoxysilane (TEOS $99 \%$, Sigma), ethanol (96\%, STANLAB), (3-Aminopropyl)trimethoxysilane (APTMS $95 \%$, Acros). All chemicals were used as received, without further purification. For the preparation of all suspensions and solutions, deionized water (Millipore, USA), was used.

The Fig. 1 presents schematic synthesis route of functionalized core/shell nanocomposites, in respect to their surface nature.

\subsection{Synthesis of $\gamma-\mathrm{Fe}_{2} \mathrm{O}_{3}$}

The maghemite nanoparticles were obtained by co-precipitation of iron(II) and (III) salts in a basic medium, reported by Massart (1981). Briefly, $20 \mathrm{~mL}$ of a $1 \mathrm{M}$ solution of $\mathrm{FeCl}_{3}$ and $5 \mathrm{~mL}$ of a $2 \mathrm{M}$ solution of $\mathrm{FeCl}_{2}$ (in $2 \mathrm{M} \mathrm{HCl}$ ), were added at room temperature to $250 \mathrm{~mL}$ of a $0.7 \mathrm{M}$ ammonia solution. The black magnetite precipitate was produced in a few seconds and kept under mechanical stirring during $5 \mathrm{~min}$. After this time, the magnetic nanoparticles were decanted by using the permanent magnet. The supernatant was removed, and moist precipitate was heated up to about $90{ }^{\circ} \mathrm{C}$, while stirring on a hot plate. After about $5 \mathrm{~min}$, magnetite nanoparticles were oxidized by adding $20 \mathrm{~mL}$ of $2 \mathrm{M} \mathrm{HNO}_{3}$ and $30 \mathrm{~mL}$ of $0.33 \mathrm{M} \mathrm{FeNO}_{3}$ to the solution. After about $1 \mathrm{~h}$ at $90{ }^{\circ} \mathrm{C}$, under mechanical stirring, the oxidation step was

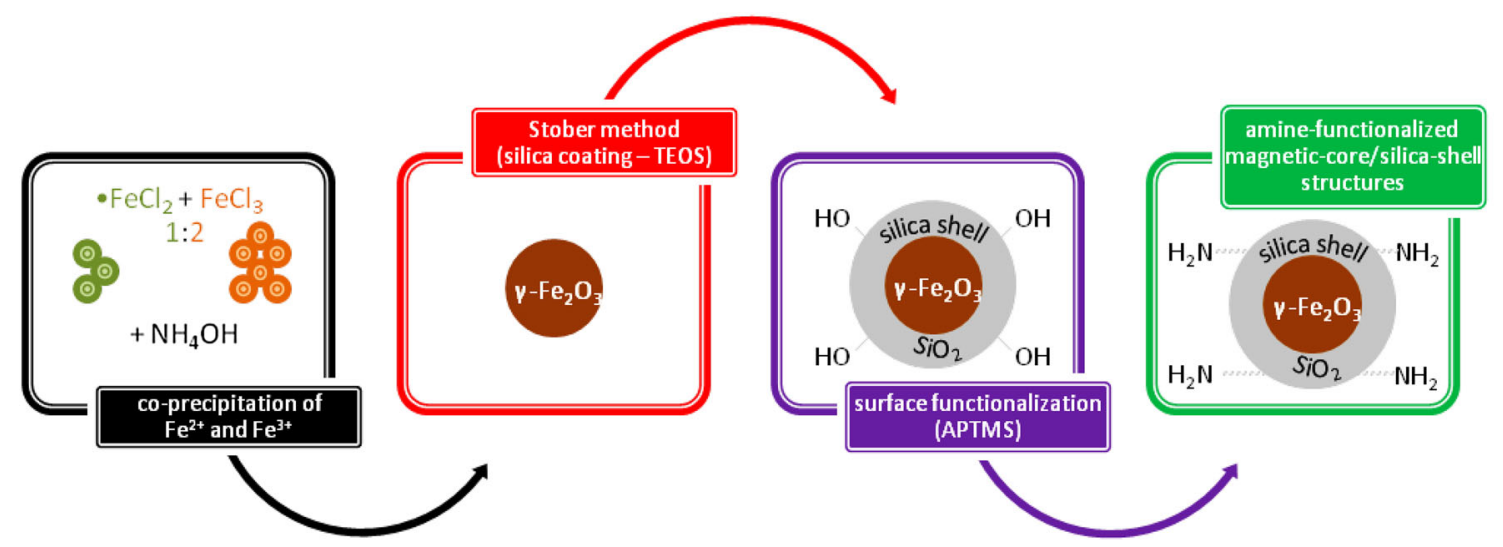

Fig. 1 Schematic synthesis route of obtaining amine-functionalized magnetic-core/silica-shell nanocomposites, illustrating the nature of the surface of the synthesized structures, in terms of the functional groups 
terminated. The dispersed maghemite nanoparticles was centrifuged and redispersed in water. The cleaning process was repeated several times. The clean naoparticles were redispersed in distilled water, to obtain the final concentration $4.72 \mathrm{mg} / \mathrm{mL}$.

\subsection{Synthesis of $\gamma-\mathrm{Fe}_{2} \mathrm{O}_{3} / \mathrm{SiO}_{2}$}

A silica shell was produced on maghemite cores using the modified well-known Stober method proposed by Salgueirino (Salgueirino-Maceira et al. 2006). Briefly, $12.44 \mathrm{~mL}$ of a maghemite suspension was added to the previously prepared solution containing $57.6 \mathrm{~mL}$ of $\mathrm{H}_{2} \mathrm{O}$, $55 \mathrm{~mL}$ of EtOH and $9.7 \mathrm{~mL}$ of $\mathrm{NH}_{4} \mathrm{OH}(28 \%)$. Finally, a solution containing $4 \mathrm{~mL}$ of TEOS in $60 \mathrm{~mL}$ of ethanol, was added to the maghemite solution. The condensation of silica shell onto magnetic nanoparticles was terminated after $4 \mathrm{~h}$. In order to minimize particle aggregation, the synthesis was carried out under mechanical stirring in an ultrasonic bath. In order to remove unreacted compounds and impurities, the magnetic-core/silica-shell structures were cleaned by repeated cycles of centrifugation, and redispersion in distilled water, to obtain the final concentration $9.9 \mathrm{mg} / \mathrm{mL}$.

\subsection{Synthesis of $\gamma-\mathrm{Fe}_{2} \mathrm{O}_{3} / \mathrm{SiO}_{2} / \mathrm{N}$}

In order to modify their surface, the magnetic silica nanoparticles were treated with (3-aminopropyl) trimethoxysilane (APTMS) (Pham et al. 2002). Briefly, $60 \mathrm{~mL}$ of silica-coated maghemite nanoparticles solution was mechanically stirred in an ultrasound bath during $10 \mathrm{~min}$. Afterwards, $0.03 \mathrm{~mL}$ of APTMS was added, and the resulting solution was stirred and sonicated for $3 \mathrm{~h}$. After this time, the nanoparticles solution was cleaned three times by cycles of centrifugation, and redispersion in water. In the final cycle, ethanol was used as a suspending liquid.

\subsection{Characterization of the obtained nanoparticles}

In order to characterize surface of the obtained nanoparticles, several analytical techniques were employed. The nitrogen adsorption/desorption isotherms were measured at $-196{ }^{\circ} \mathrm{C}$ using Nova 1200e Quantachrome Instruments analyzer. All samples were degassed at $120{ }^{\circ} \mathrm{C}$ for at least $2.5 \mathrm{~h}$ in a vacuum, prior to each measurement. The specific surface area $\left(\mathrm{S}_{\mathrm{BET}}\right)$ was evaluated in the 0.03-0.35 range of relative pressures. The average pore diameter (d) was calculated using the DFT method (Landers et al. 2013). The total pore volume $\left(\mathrm{V}_{\mathrm{p}}\right)$ was calculated by converting the amount adsorbed at a relative pressure about 0.99 to the volume of liquid adsorbate. The powder X-ray diffraction (XRD) patterns were recorded using a XRPD diffractometer (Empyrean, PANalytical). The parameters chosen for the measurement were $2 \theta$ steps of $0.013^{\circ}, 8 \mathrm{~s}$ of counting per step, and $2 \theta$ range from $5^{\circ}$ to $90^{\circ}$ at room temperature.

In order to measure the size of the obtained nanoparticles both, the microscopic observations and the diffraction laser technique (DL), were used. Transmission electron micrographs were obtained by transmission electron microscope (ZEISS Libra 120) at $80 \mathrm{keV}$ electron beam energy.

Zeta potential were measured in ZetaSizer Nano ZS (Malvern Instruments, U.K.). All measurements were performed in diluted suspensions (at concentration $100 \mathrm{ppm}$ ) in two types of media: water and electrolyte (with the fixed ionic strength $-0.001 \mathrm{M} \mathrm{NaCl}$ and $0.01 \mathrm{M} \mathrm{NaCl}$ ) at different $\mathrm{pH}$ values. $\mathrm{NaOH}$ and $\mathrm{HCl}$ were employed to adjust the $\mathrm{pH}$ values of the suspensions. All measurements were performed at room temperature.

Depending on the particle size, which was measured before, three following equations were used in order to measure the zeta potential: Smoluchowski's, Henry's and Huckel's. In apparatus (NanoZetaSizer) in which the measurements of zeta potential were carried out, there is a possibility of choice the proper equation, depending on particle radius (a) and Debye-Huckel coefficient ( $\kappa)$. In our studies, we used, as follows:

1. Huckel's equation (when $\kappa a<0.1$ )

$$
\mu_{\mathrm{e}}=\frac{2 \varepsilon_{0} \varepsilon \xi}{3 \eta}
$$

2. Henry's equation (when $0.1<\kappa a<100$ )

$$
\mu_{\mathrm{e}}=\frac{2 \varepsilon_{0} \varepsilon \xi}{3 \eta} f_{1}(\kappa a)
$$

3. Smoluchowski's equation (when $\kappa a>100$ )

$$
\mu_{\mathrm{e}}=\frac{\varepsilon_{0} \varepsilon \xi}{\eta}
$$

where $\varepsilon$-relative permittivity, $\varepsilon_{0}$-relative permittivity in vacuum, $\eta$ - viscosity of liquid, surrounding the particle; $\kappa=\left(\frac{2000 \mathrm{~F}^{2}\left(\frac{1}{2} \sum \mathrm{c}_{\mathrm{i}} \mathrm{z}_{\mathrm{i}}^{2}\right)}{\varepsilon \varepsilon_{0} \mathrm{RT}}\right)^{\frac{1}{2}}$

Sizes of particles were measured using the device Mastersizer 2000, produced by the Malvern Instruments, U.K. Monodispersity of the examined systems is confirmed by particles size measurements determined on Mastersizer. Particle sizing was determined based on the results obtained from the diffraction laser (DL) measurements. 


\section{Results and discussion}

\section{1 $\mathrm{N}_{2}$ adsorption/desorption measurements}

The nitrogen adsorption/desorption isotherms of the iron oxides are shown in Fig. 2. Shape of isotherm of the synthesized iron(III) oxide exhibits type IV according to IUPAC (Sing et al. 1985), which characterized mesoporous materials. Moreover, the obtained surface parameters confirm such structure (Table 1). In order to compare the surface parameters of synthesized-maghemite, commercial iron(III) oxide was also determined by nitrogen adsorption/ desorption measurements. Shape of this isotherm cannot be classified to any types of isotherm according to IUPAC. The commercial maghemite is characterized by less-developed porous structure (Table 1), when compared with the synthesized-one. The obtained results clearly show that the better material for further using is synthesized maghemite.

The nitrogen adsorption/desorption measurements were made only for synthesized and commercial iron oxides, because the obtained amounts of magnetic-core/silica-shell nanocomposites, as well as their amine-functionalized counterparts, were so small that it was impossible to carried out such experiments (even if the initial reactants were taken in several times more quantities). However, it can be supposed, that surface parameters after these two steps, are worse when compared with pure maghemite nanoparticles. It can be seen from TEM micrographs, that the surface of silica layer is smooth, without any apparent porosity. Thus,

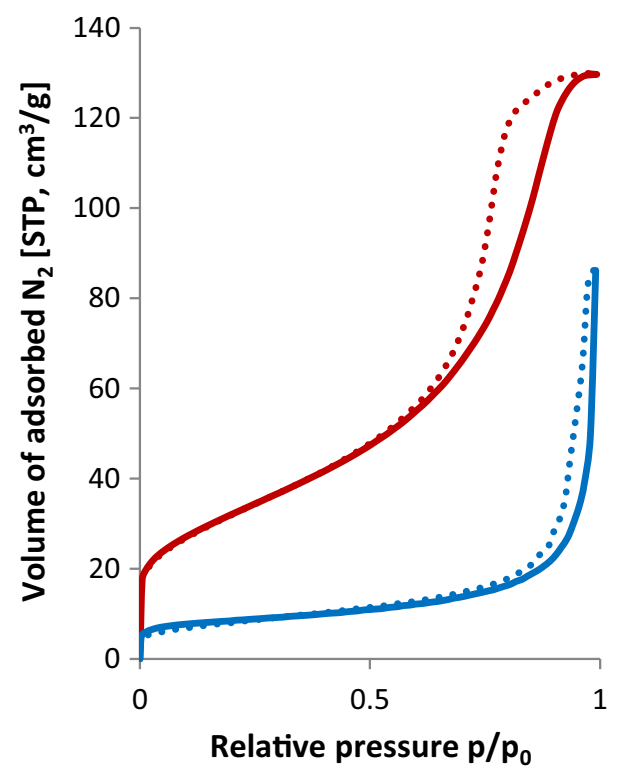

Fig. 2 Nitrogen adsorption/desorption isotherms of $\gamma-\mathrm{Fe}_{2} \mathrm{O}_{3}$ : (red line) synthesized and (blue line) commercial (Color figure online)
Table 1 Surface characterization of iron oxides

\begin{tabular}{lll}
\hline Sample & $\gamma-\mathrm{Fe}_{2} \mathrm{O}_{3}$ synthesized & $\gamma-\mathrm{Fe}_{2} \mathrm{O}_{3}$ commercial \\
\hline $\mathrm{S}_{\mathrm{BET}}\left(\mathrm{m}^{2} / \mathrm{g}\right)$ & 116 & 29 \\
$\mathrm{~d}(\mathrm{~nm})$ & 11.3 & 1.8 \\
$\mathrm{~V}_{\mathrm{p}}\left(\mathrm{cm}^{3} / \mathrm{g}\right)$ & 0.20 & 0.13 \\
\hline
\end{tabular}

it can be conclude that the specific surface area of the obtained core/shell composites, decreased.

\subsection{XRD analysis}

The X-ray diffraction patterns of all nanomaterials are shown in the Fig. 3. In order to compare the crystallographic structure of the synthesized maghemite, the XRD patterns of commercial maghemite, were also investigated. All XRD reflexes are typical of the iron oxide spinel structure $\left(\mathrm{Fe}_{3} \mathrm{O}_{4}\right.$ and $\gamma-\mathrm{Fe}_{2} \mathrm{O}_{3}$ ). The majority of reflexes match that of standard maghemite, although some of the exhibited reflexes correspond to both, maghemite and magnetite. This is due to the fact that maghemite was formed by oxidation of magnetite and that is why the crystallographic properties of both iron oxides are very similar. Thus, it is very difficult to distinguish between magnetite and magnetite/maghemite phases, because the $\mathrm{X}$-ray powder diffraction patterns are not different enough in that respect. It can be seen that the presence of seven diffraction reflexes at $2 \theta=30.20^{\circ}$, $35.45^{\circ}, 43.32^{\circ}, 53.81^{\circ}, 57.22^{\circ}, 62.98^{\circ}, 74.54^{\circ}$, corresponds to: (220), (311), (400), (422), (511), (440), (533) (in both XRD patterns), respectively. Their presence indicates that the obtained results correspond to those of reference data for $\gamma-\mathrm{Fe}_{2} \mathrm{O}_{3}$ and $\mathrm{Fe}_{3} \mathrm{O}_{4}$ (Sui et al. 2013) (according to the JCPDS cards No. 00-025-1402 and 04-009-8435, respectively). Based on those results, the maghemite phase is probably the most abundant, even up to $90 \%$ (Fig. 4).

The Fig. 3 also presents the XRD patterns of core/shell structure and functionalized core/shell structures. As before, the reflexes of maghemite are noticeable but their intensities are not as high as in the case of pure maghemite. In those two patterns, the broad diffraction peak at $2 \theta=20-30^{\circ}$ belonging to the amorphous phase of silica (Meng et al. 2015) (according to the JCPDS card No. 00-029-0085), can be observed.

\subsection{TEM and size analyses}

Microscopic observations and diffraction laser technique, were employed to determine the size of the obtained nanoparticles. Transmission electron microphotographs have been taken in order to obtain pictures of the synthesized samples. The TEM photos (Fig. 5) display the morphology of maghemite nanoparticles and magnetic silica 
Fig. 3 XRD patterns of the synthesized nanoparticles and nanocomposites: (red line) $\gamma$ $\mathrm{Fe}_{2} \mathrm{O}_{3}$-synthesized, (blue line) $\gamma$ - $\mathrm{Fe}_{2} \mathrm{O}_{3}$-commercial, (violet line) $\gamma-\mathrm{Fe}_{2} \mathrm{O}_{3} / \mathrm{SiO}_{2}$, (green line) $\gamma-\mathrm{Fe}_{2} \mathrm{O}_{3} / \mathrm{SiO}_{2} / \mathrm{N}$ (Color figure online)
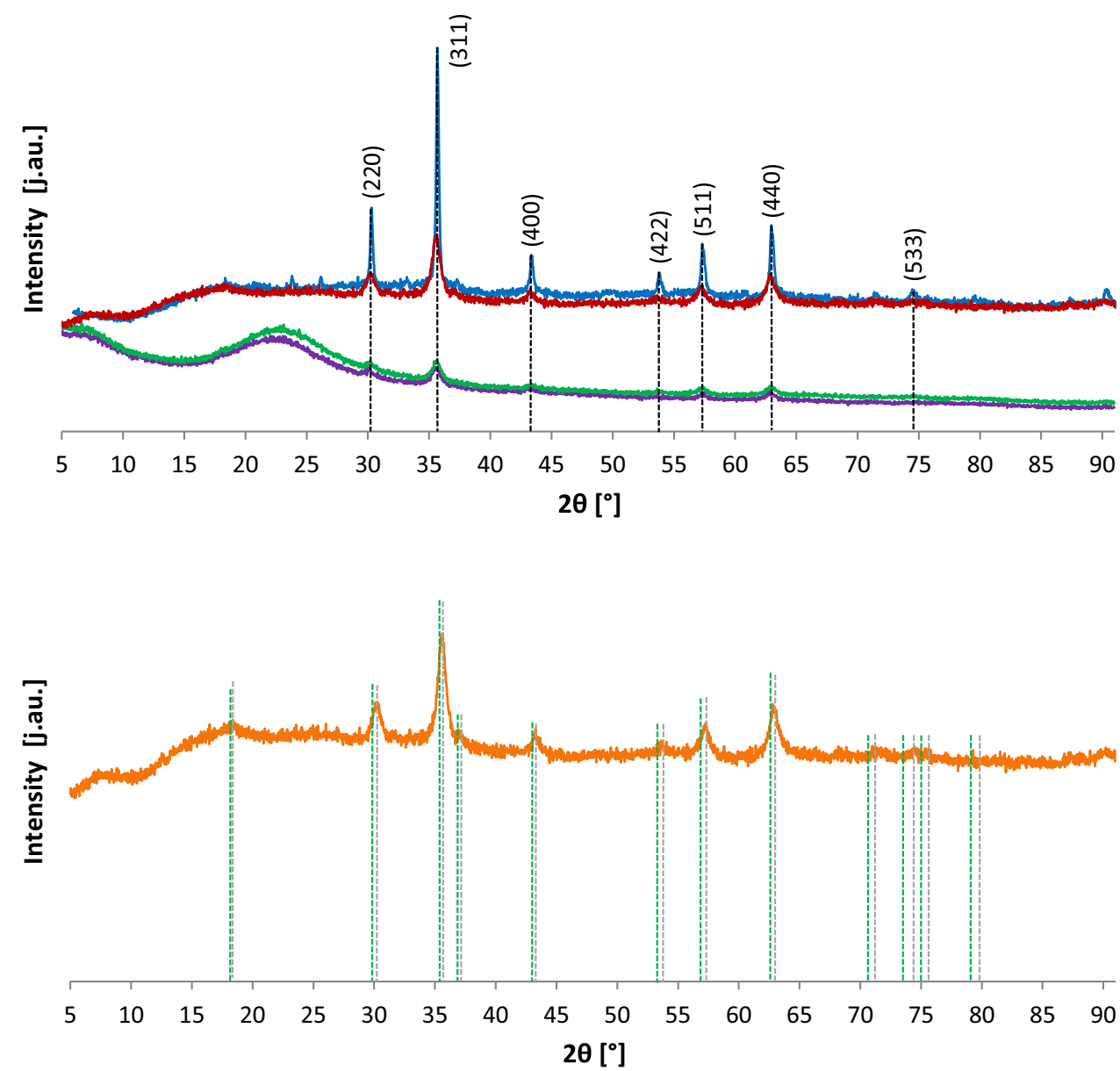

Fig. 4 XRD patterns of the synthesized iron oxide nanoparticles. Two phases (magnetite (green line) and maghemite (grey line)) are compared (Color figure online)
$56 \mathrm{~nm}$ and is smaller compared to $\gamma-\mathrm{Fe}_{2} \mathrm{O}_{3} / \mathrm{SiO}_{2}$, where the average size of particles is 62 , and $\gamma-\mathrm{Fe}_{2} \mathrm{O}_{3} / \mathrm{SiO}_{2} / \mathrm{N}$ where the average size of particles is $100 \mathrm{~nm}$. The polydispersity index (PDI) is very important in the practical point of view and is used as a measure of the breadth of the particle size distribution. PDI can be explained as a number calculated from a
Fig. 5 TEM micrographs of maghemite (a) and magneticcore/silica-shell (b) structures. Bar length: $500 \mathrm{~nm}$
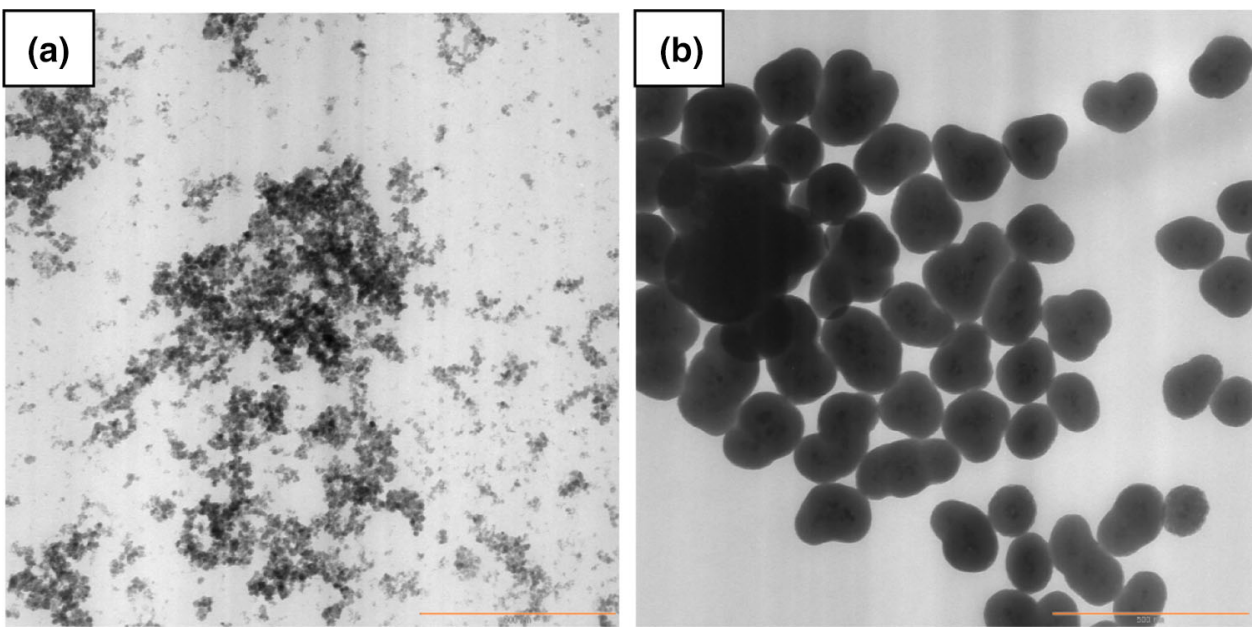

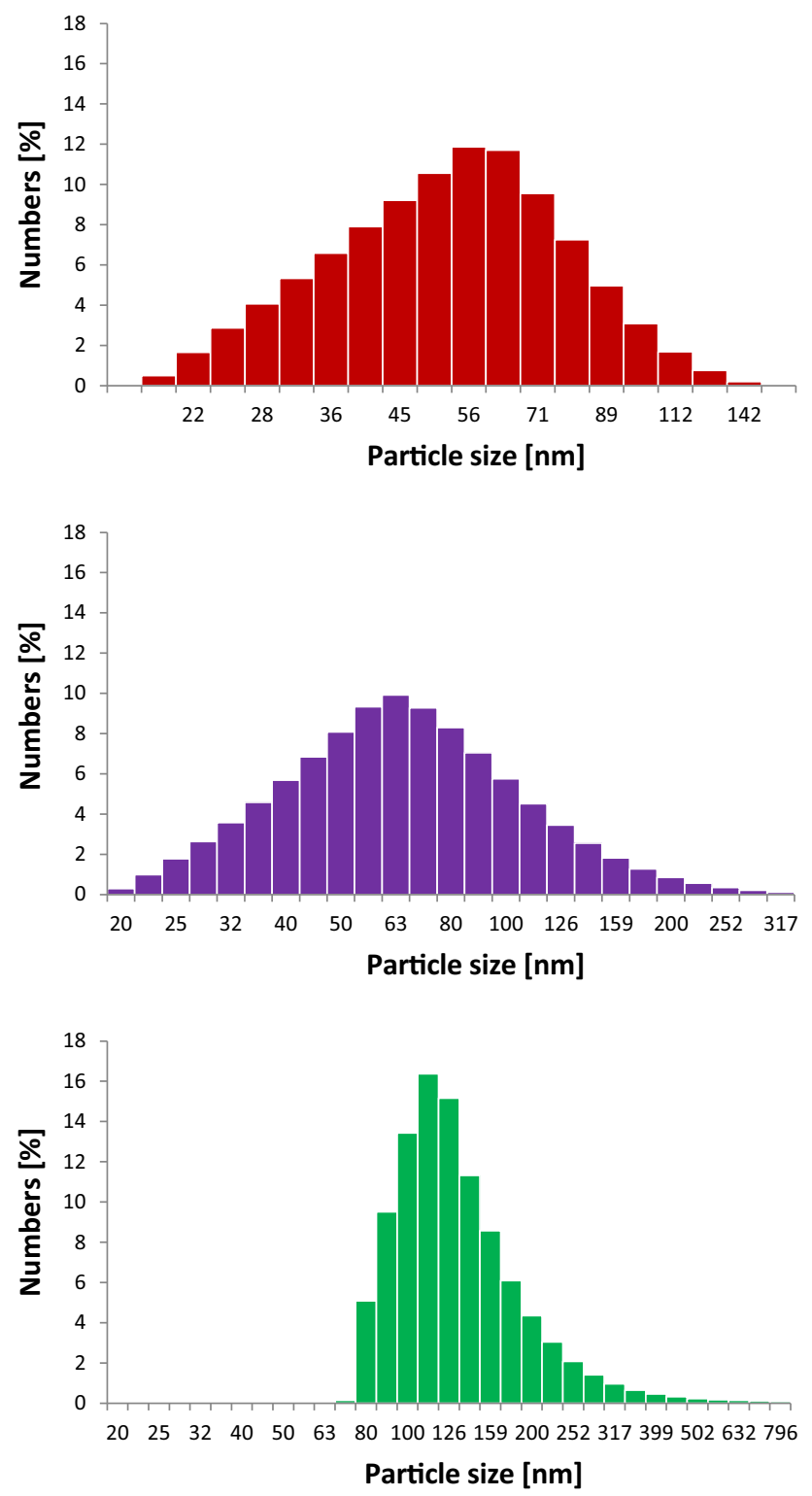

Fig. 6 Particle size distribution (by number) of the obtained samples: (red line) $\gamma-\mathrm{Fe}_{2} \mathrm{O}_{3}$, (violet line) $\gamma-\mathrm{Fe}_{2} \mathrm{O}_{3} / \mathrm{SiO}_{2}$, (green line) $\gamma-\mathrm{Fe}_{2} \mathrm{O}_{3} /$ $\mathrm{SiO}_{2} / \mathrm{N}$, obtained from the diffraction laser (DL method) (Color figure online)

simple two parameter fit to the correlation data called a cumulants analysis. The PDI is dimensionless and if its value is too big, sample cannot be measured by a proper apparatus or cannot be used in a proper measuring method. It is supposed that if value of PDI is lower than 0.25 , the system is monodisperse. The polydispersity indexes are: $0.186(\gamma-$ $\left.\mathrm{Fe}_{2} \mathrm{O}_{3}\right), 0.19\left(\gamma-\mathrm{Fe}_{2} \mathrm{O}_{3} / \mathrm{SiO}_{2}\right)$ and $0.23\left(\gamma-\mathrm{Fe}_{2} \mathrm{O}_{3} / \mathrm{SiO}_{2} / \mathrm{N}\right)$, and this confirm that the examined systems are monodispersives, and it is well correlated to TEM microscopy results.

In order to isolate maghemite nanoparticles from the surroundings, as well as improve their biocompatibility, the silica coating procedure was applied. Although, the maghemite surface is characterized by the affinity for silica, the coating process can be difficult due to aggregation of maghemite nanoparticles. Thus, more than one maghemite nanoparticle constitute the magnetic core. This effect can be observed in the Fig. 5 (right).

\subsection{Electrokinetic properties}

From the practical point of view, there is a need to control stability of magnetic nanoparticles and core/shell nanostructures. This can be tested by means of electrophoresis, which may be considered a very useful tool in the investigations of the effectiveness of the surface modification. In the Fig. 7 zeta potential as a function of $\mathrm{pH}$ of the magnetic particles, and their nanocomposites, are shown. Zeta potential allowed to determine the values of isoelectric point (IEP) of the synthesized nanomaterials. It can be seen from the attached graphs, that IEP for pure maghemite is equal to 7.5, which is in agreement with the previous results (Kosmulski 2001). This confirms that ferrofluids are only stable under strong acidic and mild basic conditions. The presence of the outer silica shell dramatically changed this value to 3.5 , which is also in agreement with the previous results (Rudzka et al. 2012) for pure silica, and $\mathrm{pH}>9$ for $\gamma-\mathrm{Fe}_{2} \mathrm{O}_{3} / \mathrm{SiO}_{2} / \mathrm{N}$. Magnetic-core/silica-shell nanocomposites are stable in a broad range of $\mathrm{pH}$ which corresponds to those for typical biological fluids. Both, the silica coating and its functionalization with amine groups result in an increased chemical stability of these colloids. Such treatments allow to obtain compatible materials, especially when they are used for biomedical applications.

For the all studied samples: $\gamma-\mathrm{Fe}_{2} \mathrm{O}_{3}, \gamma-\mathrm{Fe}_{2} \mathrm{O}_{3} / \mathrm{SiO}_{2}, \gamma-$ $\mathrm{Fe}_{2} \mathrm{O}_{3} / \mathrm{SiO}_{2} / \mathrm{N}$ the zeta potential is changing with the increasing $\mathrm{pH}$. For the pure $\gamma-\mathrm{Fe}_{2} \mathrm{O}_{3}$ sample the zeta potential values are from $+40 \mathrm{mV}$ to $-10 \mathrm{mV}$ in the studied $\mathrm{pH}$ range 2-9. The values of $\gamma-\mathrm{Fe}_{2} \mathrm{O}_{3} / \mathrm{SiO}_{2}$ sample in the same $\mathrm{pH}$ range are from $5 \mathrm{mV}$ to $-55 \mathrm{mV}$, but for $\gamma$ $\mathrm{Fe}_{2} \mathrm{O}_{3} / \mathrm{SiO}_{2} / \mathrm{N}$ from 0 to $40 \mathrm{mV}$. As follows from the zeta potential values, modification of the surface has a significant effect on both, zeta potential. The differences in the zeta potential values can also result from the changes in the surface chemistry of the studied samples which undergoes modification as a result of the synthesis. All studied systems have the $\mathrm{pH}$ range in which they are colloidally stable (Prathna et al. 2011; Eastman 2005), and thus for $\gamma$ $\mathrm{Fe}_{2} \mathrm{O}_{3} \mathrm{pH}$ 2-6 for water, $\gamma-\mathrm{Fe}_{2} \mathrm{O}_{3} / \mathrm{SiO}_{2} \mathrm{pH}$ 4-8 for all studied electrolytes and $\gamma-\mathrm{Fe}_{2} \mathrm{O}_{3} / \mathrm{SiO}_{2} / \mathrm{N}$ for $\mathrm{pH}$ 3-9 for water and $0.001 \mathrm{M} \mathrm{NaCl}$. The values of $\mathrm{pH}$ for the studied samples ensure their colloidal stability, and electrostatic repulsion forces increase, so aggregation and sedimentation rates are much lower. The zeta potential values at the $\gamma$ $\mathrm{Fe}_{2} \mathrm{O}_{3} / \mathrm{NaCl}$ interface are mainly affected by $\mathrm{H}^{+}$ions from the solution and $\mathrm{Na}^{+}$ions from the electrolyte. For the 

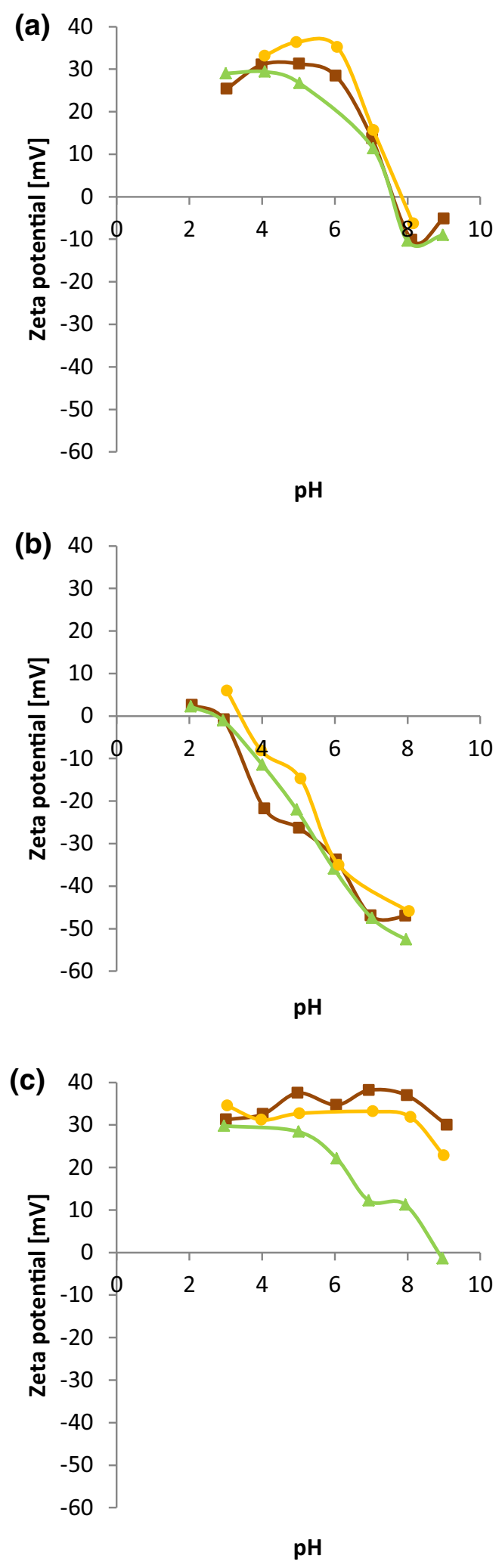

Fig. 7 Zeta potential of the obtained nanoparticles: $\mathbf{a} \gamma-\mathrm{Fe}_{2} \mathrm{O}_{3}$, b $\gamma$ $\mathrm{Fe}_{2} \mathrm{O}_{3} / \mathrm{SiO}_{2}, \mathbf{c} \gamma-\mathrm{Fe}_{2} \mathrm{O}_{3} / \mathrm{SiO}_{2} / \mathrm{N}$, in different solvents: (red square line) $0.001 \mathrm{M} \mathrm{NaCl}$, (green triangle line) $0.01 \mathrm{M} \mathrm{NaCl}$ and (yellow circled line) $\mathrm{H}_{2} \mathrm{O}$ (Color figure online) system $\gamma-\mathrm{Fe}_{2} \mathrm{O}_{3} / \mathrm{SiO}_{2}$ these are the $\mathrm{Cl}^{-}$groups from the electrolyte and $\mathrm{OH}^{-}$for the system $\gamma-\mathrm{Fe}_{2} \mathrm{O}_{3} / \mathrm{SiO}_{2} / \mathrm{N}$ mainly surface modifying organic groups. For such $\mathrm{pH}$ range values, where absolute zeta potential values are high, small average particle sizes are observed, which is in conformance with particles size determination Fig. 6. On the other hand, middle sized particles have great tendency to aggregation, which causes instability near the isoelectric point.

\section{Conclusions}

Amine functionalized magnetic-core/silica-shell nanocomposites have been synthesized and investigated using a broad range of analytical techniques. Maghemite nanoparticles were synthesized and coated with silica shell in order to improve their biocompatibility, and prevent aggregation. The obtained results of nitrogen adsorption/ desorption measurements and X-ray diffraction indicate that synthesized maghemite is characterized by better developed porous structure with good purity of $\gamma-\mathrm{Fe}_{2} \mathrm{O}_{3}$, when compared to the commercial one. The obtained TEM micrographs show that the final materials have a core/shell structure. For the all tested materials, the values of zeta potential decrease with the increasing $\mathrm{pH}$ values. Zeta potential permitted to confirm the $\mathrm{pH}$ range for the isoelectric point (IEP): 7.5 for the $\gamma-\mathrm{Fe}_{2} \mathrm{O}_{3}, 3.5$ for the $\gamma$ $\mathrm{Fe}_{2} \mathrm{O}_{3} / \mathrm{SiO}_{2}$ and $\mathrm{pH}>9$ for the $\gamma-\mathrm{Fe}_{2} \mathrm{O}_{3} / \mathrm{SiO}_{2} / \mathrm{N}$. For every of the examined systems, exists quite wide $\mathrm{pH}$ range where this systems are colloidally stable.

The existence of the silica layer changes the $\mathrm{pH}$ tendency in an important manner. $\mathrm{PH}_{\mathrm{IEP}}$ of the silica-coated maghemite nanoparticles is approximately 3.5, very distant from that of maghemite and actually closer to that of pure silica. The silica shell onto the maghemite nanoparticles causes an increase in their chemical stability, thus affecting their performance for bioapplications. It can be seen that the cationic polyelectrolyte APTMS may be employed to functionalize the magnetic silica nanoparticles, making them positive in a broad $\mathrm{pH}$ range. The presence of amine layer onto the magnetic silica surface stabilizes this colloidal nanocomposite. Ionic strength affects significantly on both, the zeta potential for pristine and amine-functionalized core/shell nanocomposites.

Acknowledgments The research leading to these results has received funding from two grants: People Programme (Marie Curie Actions) of the European Union's Seventh Framework Programme FP7/2007-2013/under REA Grant Agreement $n^{\circ}$ PIRSES-GA-2013612484 and designated subsidy of the Ministry of Science and Higher Education for scientific research or development work and related tasks, contributing to the development of young scientists and Ph.D. students, at the Faculty of Chemistry, UMCS. 
Open Access This article is distributed under the terms of the Creative Commons Attribution 4.0 International License (http://crea tivecommons.org/licenses/by/4.0/), which permits unrestricted use, distribution, and reproduction in any medium, provided you give appropriate credit to the original author(s) and the source, provide a link to the Creative Commons license, and indicate if changes were made.

\section{References}

Bele, M., Hribar, G., Campelj, S., Makovec, D., Gaberc-Porekar, V., Zorko, M., Gaberscek, M., Jamnik, J., Venturi, P.: Zincdecorated silica-coated magnetic nanoparticles for protein binding and controlled release. J. Chromatogr. B 867, 160-164 (2008)

Chen, F., Shi, R., Xue, Y., Chen, L., Wan, Q.H.: Templated synthesis of monodisperse mesoporous maghemite/silica microspheres for magnetic separation of genomic DNA. J. Magn. Magn. Mater. 322, 2439-2445 (2010)

Chibowski, S., Janusz, W.: Specific adsorption of $\mathrm{Zn}(\mathrm{II})$ and $\mathrm{Cd}(\mathrm{II})$ ions at the $\alpha-\mathrm{Fe}_{2} \mathrm{O}_{3}$ /electrolyte interface structure of electrical double layer. App. Surf. Sci. 196, 343-355 (2002)

Deng, Y., Qi, D., Deng, C., Zhang, X., Zhao, D.: Superparamagnetic high-magnetization microspheres with an Fe3O4@SiO2 core and perpendicularly aligned mesoporous $\mathrm{SiO}_{2}$ shell for removal of microcystins. J. Am. Chem. Soc. 130, 28-29 (2008)

Eastman, J.: Colloid science: Principles. Methods and Applications. Blackwell Publishing Ltd, Bristol (2005)

Giakisikli, G., Anthemidis, A.N.: Magnetic materials as sorbents for metal/metalloid preconcentration and/or separation. A review. Anal. Chim. Acta. 789, 1-16 (2013)

Guerrero-Martinez, A., Perez-Juste, J., Liz-Marzan, L.M.: Recent progress on silica coating of nanoparticles and related nanomaterials. Adv. Mater. 22, 1182-1195 (2010)

Guo, J., Yang, W., Deng, Y., Wang, C., Fu, S.: Organic-dye-coupled magnetic nanoparticles encaged inside thermoresponsive PNIPAM microcapsules. Small 7, 737-743 (2005)

Gupta, A.K., Gupta, M.: Synthesis and surface engineering of iron oxide nanoparticles for biomedical applications. Biomaterials 26, 3995-4021 (2005)

Hyeon, T.: Chemical synthesis of magnetic nanoparticles. Chem. Commun. 9, 927-934 (2002)

Kim, J., Kim, H.S., Lee, N., Kim, T., Kim, H., Yu, T., Song, I.C., Moon, W.K., Hyeon, T.: Multifunctional uniform nanoparticles composed of a magnetite nanocrystal core and a mesoporous silica shell for magnetic resonance and fluorescence imaging and for drug delivery. Angew. Chem. Int. Ed. 47, 8438-8441 (2008)

Kosmulski, M.: Chemical Properties of Material Surfaces. Marcel Dekker Inc, New York (2001)

Landers, J., Gor, G.Y., Neimark, A.V.: Density functional theory methods for characterization of porous materials. Colloids Surf. A 437, 3-32 (2013)

Laurent, S., Dutz, S., Hafeli, U.O., Mahmoudi, M.: Magnetic fluid hyperthermia: focus on superparamagnetic iron oxide nanoparticles. Adv. Colloid Interface Sci. 166, 8-23 (2011)

Laurent, S., Mahmoudi, M.: Superparamagnetic iron oxide nanoparticles: promises for diagnosis and treatment of cancer. Int. J. Mol. Epidemiol. Genet. 2, 367-390 (2011)

Lee, J., Lee, Y., Youn, J.K., Na, H.B., Yu, T., Kim, H., Lee, S.M., Koo, Y.M., Kwak, J.H., Park, H.G., Chang, H.N., Hwang, M., Park, J.G., Kim, J., Hyeon, T.: Simple synthesis of functionalized superparamagnetic magnetite/silica core/shell nanoparticles and their application as magnetically separable high-performance biocatalysts. Small 4, 143-152 (2008)
Mahmoudi, M., Sant, S., Wang, B., Laurent, S., Sen, T.: Superparamagnetic iron oxide nanoparticles (SPIONs): development, surface modification and applications in chemotherapy. Adv. Drug Deliv. Rev. 63, 24-46 (2011)

Massart, R.: Preparation of aqueous magnetic liquids in alkaline and acidic media. IEEE Trans. Magn. 17, 1247-1248 (1981)

Meng, S.C., Wang, H., Qing, M., Qiu, C.W., Yang, Y., Li, Y.W.: Preparation and characterization of $\mathrm{SiO}_{2} @ \mathrm{Fe}_{2} \mathrm{O}_{3}$ core-shell catalysts. J. Fuel Chem. Technol. 43, 692-700 (2015)

Pham, T., Jackson, J.B., Halas, N.J., Lee, T.R.: Preparation and characterization of gold nanoshells coated with self-assembled monolayers. Langmuir 18, 4915-4920 (2002)

Prathna, T.C., Chandrasekaran, N., Mukherjee, A.: Studies on aggregation behaviour of silver nanoparticles in aqueous colloids. Surf. Physicochem. Eng. Asp. 390, 216-224 (2011)

Reiss, P., Protiere, M., Li, L.: Core/shell semiconductor nanocrystals. Small 5, 154-168 (2009)

Rosena, J.E., Chana, L., Shieh, D.B., Gu, F.X.: Iron oxide nanoparticles for targeted cancer imaging and diagnostics. Nanomed. Nanotechnol. Biol. Med. 8, 275-290 (2012)

Rudzka, K., Delgado, A.V., Viota, J.L.: Maghemite functionalization for antitumor drug vehiculization. Mol. Pharm. 9, 2017-2028 (2012)

Salgueirino-Maceira, V., Correa-Duarte, M.A., Farle, M., LopezQuintela, A., Sieradzki, K., Diaz, R.: Bifunctional gold-coated magnetic silica spheres. Chem. Mater. 18, 2701-2706 (2006)

Salgueirino-Maceira, V., Correa-Duarte, M.A.: Increasing the complexity of magnetic core/shell structured nanocomposites for biological applications. Adv. Mater. 19, 4131-4144 (2007)

Schlorf, T., Meincke, M., Kossel, E., Gluer, C.C., Jansen, O., Mentlein, R.: Biological properties of iron oxide nanoparticles for cellular and molecular magnetic resonance imaging. Int. J. Mol. Sci. 12, 12-23 (2011)

Sing, K.S.W., Everett, D.H., Haul, R.A.W., Moscou, L., Pierotti, R.A., Rouquerol, J., Siemieniewska, T.: Reporting physisorption data for gas/solid systems with special reference to the determination of surface area and porosity. Pure Appl. Chem. 57, 603-619 (1985)

Sui, J., Li, J., Yang, S., Li, Z., Cai, W.: A facile method to fabricate superparamagnetic $\gamma-\mathrm{Fe}_{2} \mathrm{O}_{3} /$ silica nanotubes using multi-walled carbon nanotubes as template. Mater. Lett. 100, 32-35 (2013)

Tang, S.C.N., Lo, I.M.C.: Magnetic nanoparticles: essential factors for sustainable environmental applications. Water Res. 47, 2613-2632 (2013)

Tovmachenko, O.G., Graf, C., van den Heuvel, D.J., van Blaaderen, A., Gerritsen, H.C.: Fluorescence enhancement by metal-core/ silica-shell nanoparticles. Adv. Mater. 18, 91-95 (2006)

Tural, B., Sopaci, S.B., Ozkan, N., Demir, A.S., Volkan, M.: Preparation and characterization of surface modified $\gamma-\mathrm{Fe}_{2} \mathrm{O}_{3}$ (maghemite) - silica nanocomposites used for the purification of benzaldehyde lyase. J. Phys. Chem. Solids 72, 968-973 (2011)

Wahajuddin, Arora: S.: superparamagnetic iron oxide nanoparticles: magnetic nanoplatforms as drug carriers. Int. J. Nanomed. 7, 3445-3471 (2012)

Xia, Y., Gates, B., Yin, Y., Lu, Y.: Monodispersed colloidal spheres: old materials with new applications. Adv. Mater. 12, 693-713 (2000)

Yi, D.K., Selvan, S.T., Lee, S.S., Papaefthymiou, G.C., Kundaliya, D., Ying, J.Y.: Silica-coated nanocomposites of magnetic nanoparticles and quantum dots. J. Am. Chem. Soc. 127, 4990-4991 (2005)

Zhang, B., Xing, J.M., Liu, H.Z.: Synthesis and characterization of superparamagnetic poly(urea-formaldehyde) adsorbents and their use for adsorption of flavonoids from Glycyrrhiza uralensis Fisch. Adsorption 14, 65-72 (2008) 